\title{
A Framework for Cognitive Task Analysis in Systems Design
}

\section{Rasmussen, J.}

Publication date:

1985

Document Version

Publisher's PDF, also known as Version of record

Link back to DTU Orbit

Citation (APA):

Rasmussen, J. (1985). A Framework for Cognitive Task Analysis in Systems Design. Risø National Laboratory. Risø-M No. 2519

\section{General rights}

Copyright and moral rights for the publications made accessible in the public portal are retained by the authors and/or other copyright owners and it is a condition of accessing publications that users recognise and abide by the legal requirements associated with these rights.

- Users may download and print one copy of any publication from the public portal for the purpose of private study or research.

- You may not further distribute the material or use it for any profit-making activity or commercial gain

- You may freely distribute the URL identifying the publication in the public portal

If you believe that this document breaches copyright please contact us providing details, and we will remove access to the work immediately and investigate your claim 


\section{A FRAMEWORK FOR COGNITIVE TASK ANALYSIS IN SYSTEMS DESIGN}

Jens Rasmussen

Abstract. The present rapid development of advanced information technology and its use for support of operators of complex technical systems are changing the content of task analysis towards the analysis of mental activities in decision making. Automation removes the humans from routine tasks, and operators are left with disturbance control and critical diagnostic tasks, for which computers are suitable for support, if it is possible to match the computer strategies and interface formats dynamically to the requirements of the current task by means of an analysis of the cognitive task.

cont.

INIS Descriptors. DECISION MAKING; FUNCTIONAL ANALYSIS; HUMAN FACTORS; INDUSTRIAL PLANTS; MAN-MACHINE SYSTEMS; MONITORING; PLANNING; RISK ANALYSIS; SPECIFICATIONS. 
Such a cognitive task analysis will not ajm at a description of the information processes suited for particular control situations. It will rather aim at an analysis in order to identify the requirements to be considered along varjous dimensions of the decision tasks, in order to give the user - i.e. a decision maker - the freedom to adapt his performance to system requirements in a way which matches his process resources and subjective preferences. To serve this purpose, a number of analyses at various levels are needed to relate the control requirenents of the system to the information processes required and to the processing resources offered by computers and humans. The paper discusses the cognitive task analysis in terms of the following domains: The problem domain, which is a representation of the functional properties of the system giving a consistent framework for identification of the control requirements of the system; the decision sequences required for typical situations; the mental strategies and heuristics wrich are effective and acceptable for the different decision functions; and the cognitive control mechanisms used, depending upon the level of skill which can/will be applied. Finally, the end-users' criteria for choice of mental stategies in the actual situation are considered, and the need for development of criteria for judging the ultimate user acceptance of computer support is discussed.

Invited tutorial presented at: NATO Advanced Study Institute on Intelligent Decision Aids in Process Environments. September 1985, Pisa, Italy.

ISBN $87-550-1140-3$

ISSN $0418-6435$ 
TABLE OF CONTENTS

Page

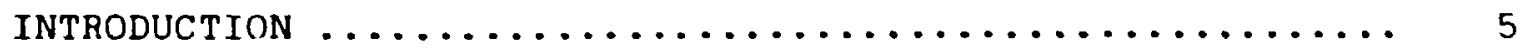

THE CONTEXT OF A COGNITIVE TASK ANALYSIS $\ldots \ldots \ldots \ldots \ldots \ldots$

THE DOMAINS OF A COGNITIVE TASK ANALYSIS ............ 10

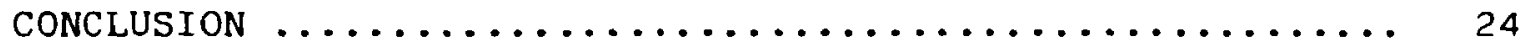

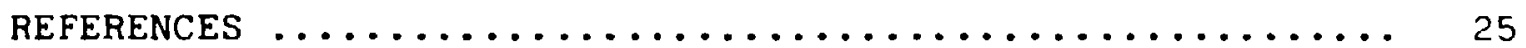




\section{INTRODUCTION}

Since some system designers may be fed up with discussions about task classification and the tedious requirements of the "timeline studies" of traditional task analysis, the present discussion will be opened by a short revieu of the development of task analysis as depending upon the technology applied for the human - work interface. Hopefully, it will be clear that not only has the content of task analysis changed, but also that the dependence of the success of a design upon the quality of a task analysis will no longer be a question of degree - which some designers might find could be reached by proper training anyhow - but that lack of task analysis for a design based on advanced information technology may very well lead to fatal failure.

The need for cognitive task analysis is rapidly growing as new information technology is introduced in the interface between humans and their work substance. Task analysis has been an important element in the Human Factors of systems design during several decades. The nature of task analysis has, however, changed significantly through this period. Several phases in this need can be identified, depending on the technology applied in the task interface.

During the early phases of the industrial development, operators were interacting directly and physically with the machinery. Instruments were sparsely used, and task analysis was not consjdered; performance depended on the general technical masterapprentice training, and work conditions could be arranged empjrically by behaviouristic time and motion studies.

As the size and complexity of industrial installations grew and electrical instrumentation technology was developed during the thirties and forties, centralised control rooms appeared. Large numbers of indicators and alarm annunciators together with operating controls were necessary, and this situation led to human factors analysis of the interface design. Still, however, there was no great need for task analysis. All primary sensorbased data were avajlable at all times, and only the physjcal appearance and arrangement of interface components had to be chosen in relation to features such as the frequency of tasks, and the relevance of the varjous indicators and control keys for individual tasks. Operators were still trajned as apprentices on older plants. Therefore, system designers only had to consider human factors as a final polish. 
This situation changed with the advent of electronic instrumentation which made high levels of automation and very sophisticated equipment technically feasible. In particular for military equipment, reliability requirements during missions pointed at the need for analysis of operator tasks and work load. Especially when process computers were applied in industrial control systems for data presentation, the need for task analysis became obvious. Data then had to be selected and grouped for presentation by means of visual display formats which were designed to match the different operating conditions and operator tasks. However, what frequently happened was an introduction of new instrumentation technology without major changes in the basic operating philosophy. Thus, the primary sensor data were still presented, but the requirements of the individual tasks and situations had to be considered on the basis of a task analysis, whi could also be used for task allocation, i.e. the distribution $O I$ tasks between operators and automatic equipment. However, this task analysis could in general be done in terms of requirements of the technical system for control operations, because it primarily serves to select data to be included in the individual display formats. Typically, very little attention was paid to the question about what the task implied in terms of human characteristics, except with respect to rather general categories of operations which were related to training and selection criteria. This kind of task analysis was described systematically by Miller (1963).

The newest stage is the use of modern information technology for preprocessing of the measured data in order to integrate basic data into messages which match an operator's needs when involved in critical decision making during disturbed system operation. The automatic equipment takes care of normal operation and all planned sequence operations on the system. The major function of the operating staff, and, therefore, the task shaping the design, is the task as supervisory controllers during emergencies. This preprocessing of information cannot be planned without an intimate knowledge of the decision strategies applied by the operators, of the subjective goal adopted, and of the mental representation of plant properties used for the task. This means that the development of a framework for cognitive task analysis is necessary, as also discussed by Hollnagel and Woods (1983) in their arguments for "cognitive systems engjneering". This kind of cognitive task analysis will have to be focused upon functional data processing aspects of the cognitive activity. 
A further development in the application of advanced information technology in human task interfaces will be the introduction of means for interactive decision making which, in the present context, involves a highly integrated cooperation between the system designer and the user with a computer as the means of communication. To the more functional information processing aspects of cognitive task analysis are then, as a result, added questions of affects and attitudes such as criteria for accepting advice, for trusting messages, for understanding a decision partner's inference. The question of task allocation changes towards allocating responsibility and authority. Decision task elements are not "allocated"; rather the role as either active decision maker or concurrent monitor is dynamically allocated to the agent with the proper resources; both partners will probably, at a more or less intuitive or rational level, have to keep track of the proceeding task simultaneously, in order to cooperate, which means to be able to take over authority and mutually to trust each other.

In the following sections, a framework for cognitive task analysis from the functional, information processing point of view is discussed.

\section{THE CONTEXT OF A COGNITIVE TASK ANALYSIS}

In the typical case, when designing human-computer systems the problem is the need to design systems for support of decision making which is also effective during situations which have not been foreseen during design, and which are not familiar to the user even if the system is operated by a group of well trained, professional users. In other cases, the problem is to design information systems which are to be operated by a wide variety of users whose background and formulation of needs are poorly known. In such cases, the design cannot be based on a detajled quantitative model of the actual information process; instead a model or conceptual framework must be used which describes the interaction in terms of related categories defining the boundarjes of a design envelope within which users can generate effective ad hoc tactics suiting their subjective preferences.

A widespread academic conception of the design process is a more or less orderly progress from a statement of the goals through 
several levels of functional formulations until, finally, the material implementation is settled. In general, iterations between the phases are included, but by and large the top-down design is accepted as the formal model.

This model does not correspond to realities, in particular not during periods with rather stable technology. Design is then largely a "horisontal" process. The previous system design is updated to be adapted to slightly changed needs or means of implementation. During such periods designers and users have a common conception of merits and difficulties by the present design and the modifications to introduce.

This approach will not be effective during periods of rapid technological changes. Designers and users will not have the same intuition, if any, and design should therefore be a more orderly top-down process. However, the benefits to be gained from new technology can only to a limited extent be formulated as design goals by future potential users. In addition, systematic top-down system synthesis is not part of many engineering curriculae, which are mostly considering analysis of systems which are supposed to be the result of the "art of enginearing". The odds are that the coming successful designs will be based on "bright ideas", "inventions", etc. The evolution of new industrial practice will typically be based on mutual industirial competition and survival of the "fittest design". But even if the design itself is not based on an expljcit conceptual framework in terms of a cognitive task analysis, such a framework will be needed for proper evaluation and documentation of the design. This evaluation and documentation will have to consider two aspects.

The first is the internal functional consistency in the design concept, j.e. whether the functional characteristics and $1 \mathrm{jmj-}$ tations of the various subsystems and pieces of equipment are both necessary and sufficient. for the overall functional requjrements. For the normal technical functions this is no major problem since $j$ t can be done empirically by prototype experiments or sjmulation facilitjes. At present, however, such empirical evaluation is not feasible for an assessment of the correspondence between the potential risk of a large-scale industrjal installation and the safety targets established for risky, but rare, events. In addition, empirical evaluation of the quality of the human-machine interface in suppcrt of operators' decision making during such events will not be feasible. For both of these features, an analytjcal assessment of the 
internal consistency of the design is necessary. This implies a check of the design concept against a conceptual model of the function of the total system which is based on a decoriposition of system function into elements at such a level that either empirical data can be collected, or the judgement of subject matter experts can be used.

As an example of the need to rationalise the consistency of industrial practice by explicitation of the design concept in a period of technological change, consider the typical alarm system of a large process plant. In a plant designed by bringing together standard equipment and subsystems, the alarm syster: is typically tre conglomeration of the warning signals which the individual suppliers consider important for the monitoring of the state of their piece (as the basis for performance guaranties). Hundreds of alarm windows presenting the state of the individual physical parameters may overload the operators' information capacity during disturbances. When the information capacity of process computers became available to control system designers, the use of alarm analysis and reduction was typically preferred to a reconsideration of the alarming philosophy and a design of an integrated control concept.

The other is the evaluation of the correspondence between the design concept and the conditions of the ultimate operation. This match has two sides. The designer can seek to predict the conditions of the final operation in his design, or the users can try to match the conditions tc the design basis. In both cases, an explicitly stated model of the cognitive task underlying the conceptual design will be necessary. This cognitive task analysis and, in particular, its preconditions in fact specify the operating conditions to be accepted by the user, and wjll be the only rationai reference for judgement of the causes of eventual malfunctioning. Unfortunately, the conceptual desigri basis is frequently very implicitly communicated. This leads to a high degree of ambiguity in the evaluation of the match between a design concept and real life conditions, in particular for the human-system interaction. The following discussion of a frame-work for cognitive task analysis attempts to formulate a model which may serve to bridge the gap between engineers' analyses of control requirements and psychologists' analyses of human capabilities and preferences. 


\section{THE DOMAINS OF A COGNITIVE TASK ANALYSIS}

For design it is necessary to structure the great variety of real life work conditions into domains which correspond to design decisions. By the use of a multi-facetted description systen it is possible to represent a great variety of conditions by a rather low number of categories in each domain, related to general features. The distinctions drawn between different domains of analysis resemble the distinctions of Leplat (1981) between analysis in terms of tasks, activities, and processes. In the present discussion, however, the denotation of task will be goal-directed activities of work in general, irrespective of the level of description. Leplat also stresses the need in system design to realise the difference between the prescribed task and the actual activity of operators. This is implicjtly done in the present approach, since the aim is design of systems in which the operators can adopt activities and mental processes according to their individual preferences while performing the tasks required by the system.

From this point of view, the following dimensions of a conceptual framework for description of a cognitive task appear to be relevant for system design:

The problem domain. The first domain of an analysis which will serve to bridge the gap between the purely technical analysis of a system and the psychological analysis of user resources should represent the functional properties of the system in a way which makes it possible to identify the control requi rements of the system underlying the supervisory task. This is an engineering analysis in technical systems terms and will result in a representation of the problem space. An appropriate representation should reflect the varying span of attention in the part/whole djmension, and the varying level of abstraction in the means/end dimension. Change in representation along both dimensions is by designers and operators in order to cope with the complexity of a technical system, depending upon the situation and the phase of a decision task (Rasmussen, 1984).

The means-end dimension is illustrated by the abstraction hierarchy of Figure 1, in which representations at low levels of abstraction are related to the avallable set of physical equipment which can be used to serve several different purposes. Representations at higher levels of abstraction are closely related to specific purposes, each of which can be served by 


\section{LEVELS OF ABSTRACTION}

\section{FUNCTIOMAL PURPOSE}

PRODUCTION FLOM MODELS.

CONTROL SYSTEM OBJECTIVES ETC.

\section{ABSTRACT FUNCTION}

CAUSAL STRUCTURE, Mass, EMERGY 8 INFORMATION FLOW TOPOLOGY, ETC.

\section{GENERALISED FUNCTIONS}

"STANDARd" functions \& processes. CONTROL LOOPS, HEAT-TRANSFER, ETC.

\section{PHYSICAL FUMCTIONS}

ELECTRICAL, MECHANICAL, CHEMICAL PROCESSES OF COMPONENTS AND EOUIPMENT

\section{PHYSICAL FORM}

PHYSICAL APPEARAMCE AND ANATOMY, MATERIAL \& FORM, LOCATIONS, ETC,

igure 1. The functional properties of a physical process system can be described at several levels of abstraction, representing the functional purpose and the physical implementation in different degrees in a means-end hierarchy. (Reproduced from Rasmussen (1983) with permission from IEEE). 
different physical arrangements. This hierarchy is therefore useful for a systematic representation of the mappings in the purpose/function/equipment relationship which is the context of supervisory decision making. The relationship is a complex manyto-many mapping without which there would be no room for choice or supervisory decision making. According to Ashby's (1960) law of requisite variety, this mapping will have to be increasingly complex as the variety of abnormal situations which must be controlled successfully is increasing as jt is the case in modern large-scale industrial operations. The increasing complexity makes it more and more likely that an operator may test an erroneous but quite reasonable hypothesis by actions upon the system (Rasmussen, 1984) and thereby change a minor incident into an accident. Similar lines of reasoning have led perrow (1984) to introduce the notion of the "natural accident".

Considering a control task at any level of the hierarchy, information about the proper function, target states, and answers to the question "why" is obtained from the level above, while information about present limitations and available resources, i.e. answers on the question "how", can be obtained from the level below. In the context of supervisory control, the focus is upon those functions in human-machine systems which are related to correction of the effects of faults and other disturbances. Operational states can only be defined as disturbed or faulty with reference to the planned or intended functions and purposes. Causes of improper system functioning depend on changes in the physical world. Thus they are propagating - and explajned - bottom-up in the hierarchy. In contrast, reasons for proper system functions are derived top-down in the hierarchy from the functional purposes considered during design.

During plant operation, the task of the supervisory controller human and/or computer - will be to ensure that proper actions are taken to match the actual state of the system with the target state specified from the intended mode of operation. This task can be formulated at any level in the hierarchy. During plant start-up, for instance, the task moves bottom-up through the hierarchy. In order to have an orderly synthesis of the overall plant function during start-up, it is necessary to establish a number of autonomous functional units at one level before they can be connected to one function at the next higher level. This definition of functional units at several levels is likewise important for establishing orderly separation of functional units for shut-down and for reconfiguration during periods of malfunction. 
During emergencies and major disturbances, an jmportant supervisory control decision is the selection of the level of abstraction at which to consider the control task. In general, the highest priority will be related to the highest level of abstraction: First consider overall consequences for plant production and safety in order to judge whether the plant m.sde of operation should be switched to a safer state (e.g. standby or emergency shut-down). Next, consider whether the situation can be counteracted by reconfiguration of functions and physical resources. This is a judgement at a lower level representing functions and equipment. Finally, the root causes of the disturbance are sought to determine how it should be corrected. This involves the level of physical functioning of parts and components. Generally, this search for the physical disturbance is of the lowest priority, aside from the role which knowledge about the physical cause may have for understanding the situation.

The actual content of the information about the design basis which is necessary to enable operators to make the appropriate decisions should thus be identified from the abstraction rierarchy:

For prediction of responses of the system to control inputs in supervisory control decisions, knowledge about functional relations at each of the levels in the hierarchy is necessary. This includes knowledge of plant anatomy and spatial arrangements at the lowest level of physical form. At the level of physical functinn, important information is the description of the functioning of equipment, for instance, in the form of pressure-flow-rfm charts for pumps, reactivity-power equations for nuclear reactor cores, etc. Possibilities at the level of more generic functions are phase plots for water-steam systems ("steam tables"), heat transfer characteristics of cooling circuits, and control strategies for automatic controllers. More general characteristics in terms of power and inventory balances will be typjcal of more abstract functional requirements. Fjnally, at the level of functional purpose, the production requirements and the specifications of risk targets and linits for dangerous releases are given.

This kind of information, describjng relationships within each level of the hierarchy, will in general be immediately access-. ible in engineering manuals and system descriptions. Such information as well as descriptions of the functional mapping upwards in the hierarchy are typically related to established and 
well documented methods for engineering analysis. This is not the case for information describing the downward mapping which represents the design decisions; i.e. the reasons behind the chosen implementations. This information is typically implicitly found in company or engineering practice or is based on the designer's personal preferences and seldom finds its way to the operators. This may be crucial for control decisions when overruling of a design requirement, e.g. an interlock protection, has to be considered during critical situations. In this way, reasons for fatal operator decision errors may be propagating downward in the hierarchy. Traditionally, much effort is spent on presenting operators with analytical, bottom-up information about the system. Only little attention has been paid to the need for top-down, intentional information on reasons for the implementations chosen durir: the design. To give access to such information, ad hoc advice facilities are typically established in the form of technical supervisors on call and - in the nuclear industry - "resident technical advisors" and "technical support centers". This kind of information should be directly available to the operating staff, probably in a kind of "expert system" computer-based tutoring system.

The lack of information on reasons will probably not be a problem in systems of moderate size and risk levels, for which only the rather frequent operational states have to be considered since the reasons for these will be immediately and empirically known to the operating staff, because their effects are frequently met. This is not the case for large systems where safety specifications also have to consider rare events. In such systems, reasons for infrequent yet important functions may be much more obscure to operators and special means may be required to make them understood. The information can be difficult to collect, once the design has been completed. It is a frequent experience for operating organisations that questions to system suppliers concerning their design bases are hard to have answered; typically, minutes from project meetings have to be retrieved since the man having the knowledge has moved to another position. Information representing reasons for design choices, for production and safety policies in a company will have the character of heuristic rules which are verbally stated, and an information base in the form of an "expert system" and an "expert knowledge acquisitjon" program to collect such information may be a useful tool for alleviating these difficulties.

The decision sequence. The next domain of analysis to consider is related to the decision process which has to be appljed for 


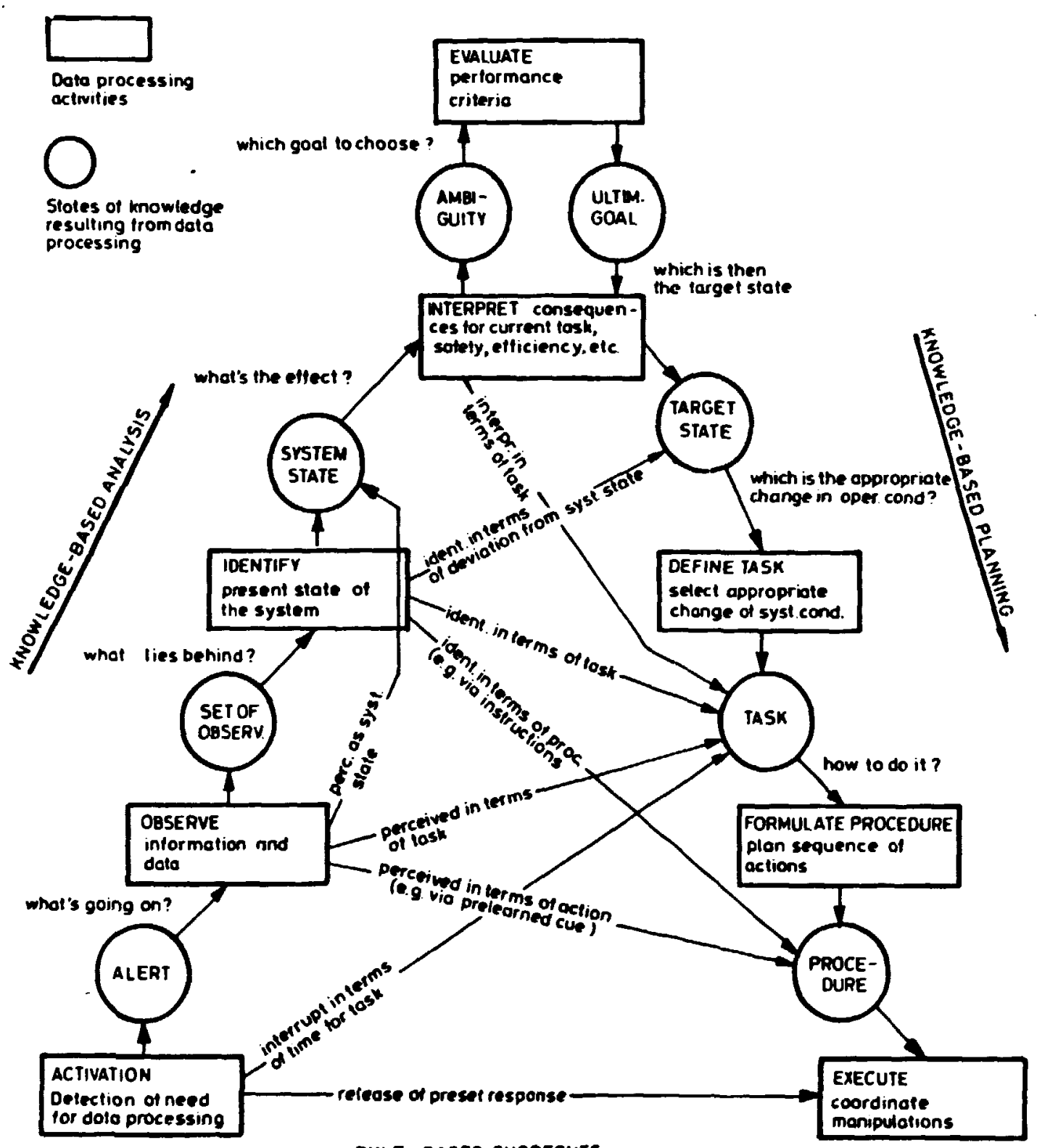

RULE - BASED SHORTCUTS

Figure 2. Schematic map of the information processes involved in a control decision. Rational, functional reasoning connects the "states of knowledge" in the basic sequence. Stereotyped processes and heuristics can by-pass intermediate stages. (Adopted from Rasmussen (1976) with permission from Plenum Press). 
operation upon the problem space. It is generally accepted that the decision process can be structured into a fairly small number of typical decision processes representing the various phases of problen analysis and diagnosis, evaluation and choice of goal priority, planning of resources, and, finally, execution and monitoring, see Figure 2.

Human mental economy can be achieved by the partitioning of a complex process in subroutines connected by more or less standardised key nodes representing states of knowledge useful for linking different processes, for bringing previously successful subroutines into use in new situations, and for communicating with cooperators in decision making. This is important since the task will be shared by the operator, the computer, and the systems designer. The task analysis will have to consider whether the decision is to be based on the designer's analysis a priori, and stored in the system by means of operational instructions and/or computer programs in order to ensure proper treatment of, for instance, rare event risk considerations, or whether the decision must be left for an on-line evaluation by operators and/or computers, see the example in Figure 3.

At this level the task analysis will be in implementationindependent terms, and will include an identification of the cognitive control mechanism required; i.e. which of the subroutines that can be preplanned routines called from memory, and which must be organised ad hoc. The decision ladder model of Figure 2 can be used as a scratch pad to represent the allocation of the different phases to the designer, the computer, and the operating staff.

Mental strategies and heuristics. An analysis in this problem domain can serve to identify those information processing strategies which are effective for the different phases of the decision sequence in order to identify the required data, control structures, and processing capacities. It is generally found that a given cognitive task can be solved by several cifferent strategies varying widely in their requirements as to the kind of mental model and the type or amount of observations required (see for instance for concept formation: Bruner et al., 1956; for trouble shooting: Rasmussen et al., 1974; and for bibliographic search: Pejtersen, 1979). An analysis of the task is therefore important in order to jdentify the different: strategies which may be used to serve the different phases of the decision sequence, and to select those which are considered effective and reliable. 


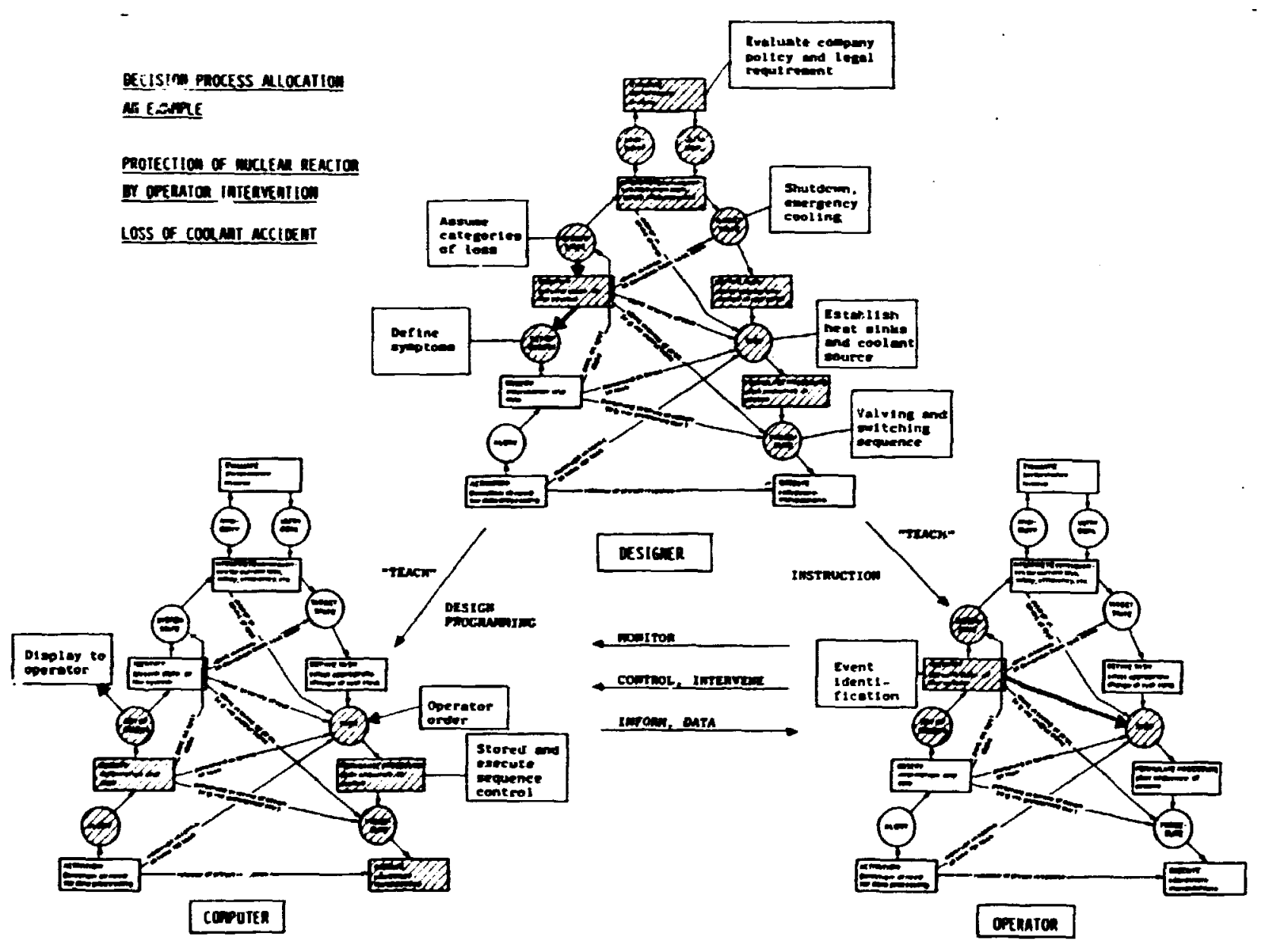

Figure 3. The figure illustrates the role of the designer, the cperator, and a computer in a control decision which has only been partly automated. The designer has planned a repertoire of protective sequences which are stored in a computer, but left the diagnosis to an operator. In addition to the decision functions, the designer, operator, and computer can support each other in different inform/advice/teach/learn functions. 
This analysis, which is related to operations research rather than psychology, identifies the information processes required in implementation-independent terms as a basis for a subsequent human-computer task allocation based on demand/resource matching. It may be difficult to identify the useful, possible strategies by rational analysis, but since users are very inventive regarding identifying clever tricks, the strategies may be identified by empirical studies of user behaviour. This, of course, requires psychological as well as domain expertise.

An important part of the analysis is an identification of the general resource requirements of the strategies in terms of data about the actual system state, on the basic functional relations, the processing capacity needed, etc., and of the consequences of errors. The results will be the basis for matching these requirements with the resource characteristics of the designer, the computer, and the operating staff for planning of their roles in the interactive decision task.

In addition, guides can be obtained for selection of suitable support of the mental models required in terms of information content of suitable display formats and the data integration required. It is the design objective to match the displays to the mental model which bill be effective for the task and to choose interface design, operator selection and total job content in a way which will guide operators' subjective preferences in that direction. It should be noted that different strategies will have very specific needs with respect to type of useful data, to support of the mental model etc., and that in "intelligent" decision support systems it should be possible to let a computer analyse the user queries in order to jdentify the user's strategy and then to supply the required support in displays and messages of the proper form. The system should develop a model of the user (Hollnagel and Woods, 1983).

Cognitive control domain. While the information content which should be included in the display formats to support the decisions of a supervisory controller is jdentified from a task analysis, the form of the displays should be selected from consideration of human cognitive control mechanisms. This is necessary in order to have an interface design which will lead the future users to develop mental models and heuristic rules which will be effective for the information processing strategies chosen as the design basis. The model of human information processing used should be able to represent the different cognjtjue control mechanisms which are active at different levels of 
training, $i$. e, during routine as well as unfamiliar situations. The level of training will determine the domain of cognitive control and, thereby, the nature of the information used to control the activity and the interpretation of observed information. Control may depend on a repertoire of automated behavioural patterns, a set of state-action production rules, or problem solving operations in a symbolic representation. And, consequently, the same display con:iguration may be interpreted as a pattern of signals for control of direct sensori-motor manipulation, as signs which may act as cues for release of heuristics, or as symbols for use in functional inference. If the same display configuration is to support the skilled expert's heuristics as well as the analysis of the novice, careful analysis is necessary of the potential for interpretation of the displayed information as signal, signs, or symbols related to the task (Rasmussen, 1983).

Another important aspect of the model of cognitive control structures will be its use to identify mechanisms leading to errors in human performance. It seems to be possible to account for a majority of the frequent slips and mistakes by a limited number of cognitive mechanisms closely related to learning and adaptation (Reason, 1982, 1985; Rasmussen, 1984). In short, such mechanisms are related to interference due to similarities between cue patterns releasing stereotyped actions, between automated movement patterns, etc. An important part of a cognitive task analysis can be to screen the cognitive activities related to crucial decisions in order to identify sources of interference from "similar", typically more frequent task sequences. This points to the fact that cognitive task analysis may not only have to consider selected critical tasks; i.e. the general background of "trivial" activities is important. Such tasks are the source of the general level of training, of the large repertoire of automated routines which may be the raw material for composing special procedures, and which is with certainty the source of interference with less familiar activities. A model which seems to be promising for this kind of analysis is presently being developed by Reason (1985).

In a consideration of the cognitive control structures, it will be important to treat facilities for error recovery in a cognitive task analysis. The control domain applied for control of a current activity may not be the one needed for detection and recovery from own errors, and this will have ramifications for interface design which must both support the control task and 
enhance error detection and recovery. A special analysis should be applied for evaluation of error recovery features.

This kind of analysis depends on a model of the cognitive behaviour of a human in a complex interaction with the onvironment which depends upon experience across time and tasks. Since such a model should be able to predict the relationships among elements of behaviour which are typically studied by separate branches of psychology, it has to be a model at a higher level than the usual psychological models, as Hollnagel and Woods (1983) argue, "the whole of a man-machine system is more than the sum of its parts." There are, of course, limitations in the present analytical models of human behaviour as it will also be demonstrated in the discussion in the sections below, but this should not prevent the use of the existing models to guide designers in the direction of more user-friendly and errortolerant systems, by identifjcation of features defining boundaries of the domains within which it is possible to generate acceptable performance.

The analyses discussed so far have been considering the elements of the stepwise transformations from the functional properties of the physical system to the operator's interpretation of the messages presented by the decision support system, which are jliustrated by the left column of Figure 4. In addition to the effects of this path of interaction, an operator's responses will be depending upon his mental models and strategies achieved from his professional training and general technical background. To ensure compatibility between the mental models and strategies adopted for interface design and those developed during training, a cognitive task analysis should also be the basis for planning of training programs, whether it be class room or simulator training. Development of schemes for training djagnostic skills within petrochemical industries, based on analysis of expert troubleshooters' strategies, seems to indicate a potential for great improvements compared with the present tradition (Shephard et al., 1977).

Finally, stop rules for the level of detajl to include in a cognitive task analysis may be derived from consideration of the cognitive control domain necessary. Model-based analysis will be necessary only to the level of automated subroutines, which may be much more reliably planned from empirical studies and human factors handbooks. The stop rule in task analysis for planning of trajning programs proposed by Annett et al. (1977) seems to be useful also in the present context. According to their stop 


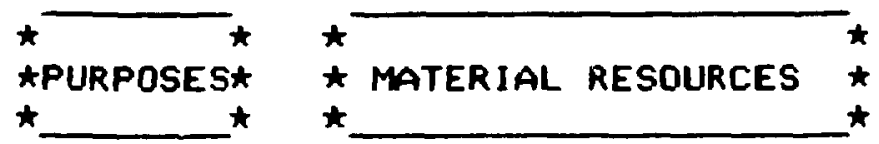

Engineering analysis
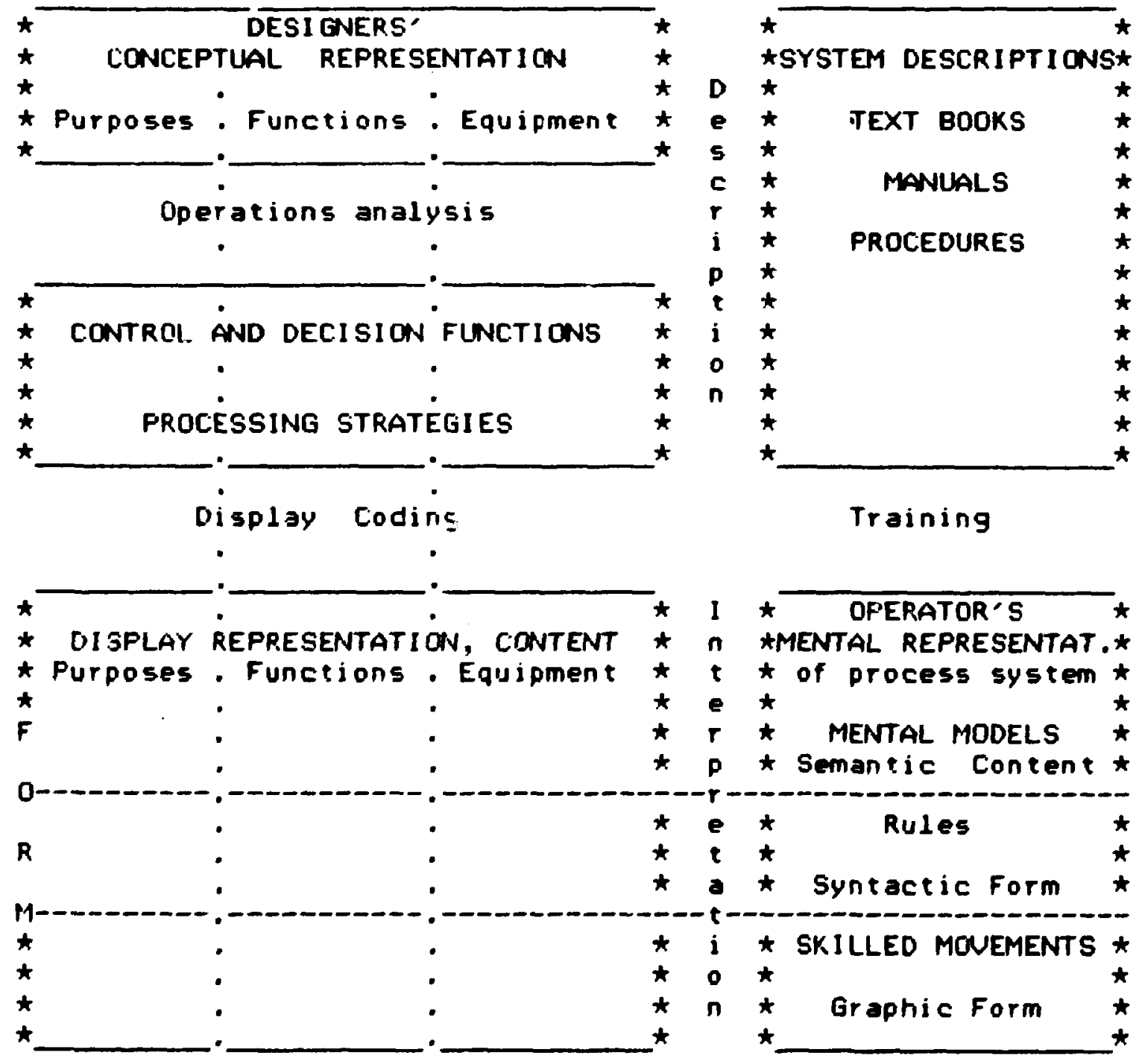

Figure 4. A schematic map of the different representations of a process system which are relevant for a cognitive task analysis. The aim of such an analysis is an integrated consideration of these representations and their mutual compatibility. During design, analysis along the path represented by the left hand column should ensure proper content of the displayed information. The form will depend on the level of cognitive control which the display is intended to activate. This form should match the preconditions for interpretation prepared by the communication through the right hand training path. 
rule, task analysis will be terminated when the product of the frequency of a subtask and the cost of error in its execution are below a certain value, since analysis can then be replaced by observation, or benefit from improvements will be marginal.

Criteria for choice of mental stategies. The requirement that the interface design should lead operators to form effective mental models and adopt proper strategies presupposes that it is possible to characterise the different strategies with respect to features that are related to the users' subjective criteria for choosing a given strategy as the basis for their performance. The criteria for this choice will frequently depend on properties of the information process itself, rather than $j$ ts result. This requjes an analysis in the borderline between operations research and psychology, and represents an area where laboratory experiments and generalisations from various real life analysis can be very fruitful. Some results are available, indjcating important process criteria, such as cognitive strain, load on short-term memory, cost of observation, time available, data and resource limitations in general, cost of mistakes, etc. (Bruner et al., 1956; Rasmussen et al., 1974). More research in this area is needed. Interface design and computer support of decision making will only be successful if based on a proper knowledge of the performance criteria anc subjective preferences the user will apply for the chojce of strategy in the actual situation.

Role allocation. In addition to the support given in the problem solving process proper, there will be a need for exchange of background information. The designer, coriputer or the end-user may possess knowledge or data useful in the other partnars' running task because of better memory characteristics, other information sources, etc. What does the designer/computer/user know which the partner needs?

Interactive decision making is sometimes considered to be based on a - static or dynamic - task allocation, where the cooperators are allocated functions and exchange results at suitable "states of knowledge". This is a realistic picture of the communication during rather familiar situations. However, when unusual situations occur, it will be necessany to have a much more intimate cooperation. During such situations human cooperators typically engage in a discussion to elaborate on precondjtions of interpretation of observations, on the status and orjgin of their mental model, relevance of previous experience, etc., a conversation which seems to be a prerequisite for understanding 
messages and accepting advice. Such interaction takes place whenever the course of events or the partners' responses do not conform with intuitive expectations.

This mesns, in fact, that for systems intended for interactive decision making or "intelligent" support, it is not a question of allocating information processing functions, but of allocating authority and responsibility - to designer or user. The decision partners on site, the operator and the computer, who are the representatives of the designer, and who have to complete the design of control strategy for the particular unforeseen event, in reality have to operate in parallel during the process in order to be able to communicate meaningfully. The question only is who is responsible and has to be consistent and complete, and who is allowed to be satisfied with the intuitive hunches and approximate estimates sufficient to understand and trust the partners' messages. The problem for cognitive task analysis is to determine what kind of information should be communicated, and which "states of knowledge" in the information process of the computer are suited for communication to match the processing and expectations of the user and prepare him to take over. Typically, the information processes suited for the computer and for the human decision maker will be very different and, therefore, the necessary key nodes for exchange of information should be very carefully chosen. This conmunication will include messages in the whole range from neutral nessages concerning background information, over advice or recommendations on useful approaches, to instructions and strict orders. Which are the criteria for the users' acceptance of the messages in the sense they are meant? What constitutes the difference in the conditions leading to cooperation, compared with those leading to rejection of support and to a competitive interaction?

Very little research is available in this area. The discussions in existing general textbooks focus, however, on aspects of preconditions for advice acceptance which are relevant for design of decision support systems. Nowell-Smitr: (1954) discusses different categories of communication which are relevant in this respect, such as: Learning, instruction, advice, exhortation, and command. He also mentions a number of ways in which apiece of advice can go wrong: The adviser deliberately deceives, he mistakes facts or conditions, he is inappropriately assuming that the advisee has the same perception of the problem as he himself has, the advice is excellent but unforeseen conditions emerge and, finally, he did not know what the problem is. Except. for the first, these are all conditions which may serve to 
decrease an operator's confidence in a designer's attempts to help. In his discussion of possible criticism of advice, Gauthier (i963) notes: "The nisuse of advile is subject to the law of diminishing returns; extend it too far, and no cne will seek or attend to advice". This statement could have been addressed to some of the alarm analysis concepts mentioned earlier. A designer's pre-analysis of alarm pattems will probably be trivial to operators in frequent situations, and wrong in the more complex ones.

howland et al. (1976) analyse trustworthiness of communication and $f$ ind that "an individual's tendency to accept a conclusion advocated by a given communicator will depend in part on how well informed and intelligent he belieres the communicator co be. However, a recipient may believe that a communicator is capable of communicating ralid statenents, but still be inclined to reject the communication if re suspects the conmunicator is motivated to make non valid asserticrs. It seems necessary, therefore, to make a distinction between 1) the exterit to which a communicator is perceived to be a source of valid assertions (his "expertness") and 2) the degree of confidence in the communicator's intent to comimunicate the assertions he considers most valid (his "trustworthiness?". These aptear to be key questions when a designer by means of his analysis of hypothetical scenarios attempts to assist an operator unknown to him diring a complex situation in a distant future.

In general, research in this area seems to be related to activities such as social counselling, educational guidance, advertising and political propaganda, which means that research related to computer-based decision support systems should be considered a high priority research area.

\section{concusion}

In this framework for cognitive task analysis, the important feature is not the detailed form of the models underlying the analysis at the various domains. The most important aspect is the attempt to identify a set of dimensions in a multi-facetted description of the intelligent task a human and a conputer are supposed to perform in cooperation. The concepts used in the dimensions should be able to bridge the gap between an en- 
gineering analysis of a technical system and a psychological description of human abilities and preferences in a consistent way, useful for systematic design. At the same time, the concepts should be compatible with those used for analysis of control and computer systems.

The present discussion of cognitive task analysis is only considering the concepts related to the content of the communication to be considered in the design of intelligent decision support systems, i.e. the representations of the problem domain, the control decisions to be made, and the decision strategies which will be applicable. For a successful design of the form of displays and other means of communication, including tools for effective information retrieval, models of human preferences and criteria for choice of the ultimate approach by the users are necessary (Woods, 1984). Development of such models requires analysis of humail performance in real decisio. situations, either from actual accident scenarios (Pew et al., 1981; Reason, 1982; Woods, 1982) or during complex simulated scenarios (Woods et al., 1981).

\section{REFERANES}

Annett, J., Duncan, K. D., Stammers, R. B., and Gray M. J. (1971): Task Analysis. Training Information, Paper 6, Department of Employment. London: Her Majesty's Stationary office.

Ashby, H. R. (1960): Design for a Brain. London: Chapman \& Hall. Bruner, J. S., Goodnow, J. J., and Austin, G. A. (1956): A Study of Thinking. New York: Wiley.

Gauthier, D. P. (1963): Practical Reasoning. Oxford: Clarendon Press.

Hollnagel, E. and Woods, D. (1983): Cognjtive Systers Engineering: New wine in New Bottles. Int. J. of Man-Machine Studies, 18 , p. 583-600.

Hovland, C. I., Janis, I. L., and Kelley, H. H. (1976): Communjcation and Persuation. Yale Univ. Press.

Leplat J. (1981): Task Analysis and Activity Analysis in situatjons of Field Djagnosis. In J. Rasmussen and $W$. B. Rouse (Eds.): Human Detection and Diagnosis of System Fajlures, New York: Plenum Press. 
Miller, R. B. (1963): Task Description and Analysis. In: R. M. Gagne (Ed.): Psychological Principles in System Development, 187-228. New York: Holt, Rinehart and Winston.

Nowell-Smith, P. H. (1954): Ethics. Penguin books.

Pejtersen, A. M. (1979): Investigation of Search Strategies in Fiction Based on an Analysis of 134 User-Librarian Conversations. In: IRFIS 3. Proceedings of Third International Research Forum in Information Science. Oslo, August 1-3. Statens Biblioteksskole, 0slo. pp. 107-132.

Perrow, P. (1984): Natural Accidents. New York: Basic Books.

Pew, R. W., Miller, D. C., and Fehrer, C. E. (1981): Evaluation of Control Room Improvements through Analysis of Critical Operator Decisions. EPRI NP-1982.

Rasmussen, J. (1976): Outlines of a Hybrid Model of the Process Operator. In Sheridan, T. and Johannsen, G. (Eds.): Monitoring Behaviour and Supervisory Control. Plenum Press.

Rasmussen, J. and Jensen, A. (1974): Mental Procedures in Real Life Tasks: A Case Study of Electronic Trouble Shooting. Ergonomics, Vol. 17, No. 3, pp. 293-307.

Rasmussen, J. (1983): Skills, Rules, Knowledge; Signals, Signs, and Symbols; and Other Distinctions in Human Performance Models. IEEE Transactions on Systems, Man, and Cybernetics, Vol. SMC-13, No. 3.

Rasmussen, J. (1984): Human Error Data. Facts or Fiction? 4 th Nordic Accident Seminar. Rovaniemi, Finland. Risø-M-2499.

Rasmussen, J. (1984a): Strategies for State Identification and Diagnosis. In W. B. Rouse (Ed.): Advances in Man-Machine Systems Research, Vol. 1, J.A.I. Press, Greenwich Co.

Reason, J. T. and Myclelska, K. (1982): Ahsent-Minded? The Psychology of Mental Lapses and Everyday Errors. Englewood Cliffs: Prentice-Hall.

Reason, J. (1985): General Error Modelling System (GEMS). In: Rasmussen, Duncan, and Leplat (Eds.): New Technology and Human Error. Proceedings of 1st Workshop on New Technology and Work. Bad Homburg. To be published.

Reason J. (1985a): Recurrent Errors in Process Environment, Some Implications for the Design of Intelligent Decision Support Systems. Proceedings of NATO Advanced Study Instj.tute on Intelligent Decision Aids in Process Environment. September 1985, Pjsa, Italy. Springer Verlag. To be published.

Shepherd, A., Marshall, E. C., and Duncan, K. D. (1977): Djagnosis of Plant Failures from a Control Panel: A Comparison of Three Training Methods. Ergonomics, Vol. 20, pp. 347-361.

Woods, D. D., Wise, J., and Hanes, L. (1981): An Evaluation of Nuclear Power Plant Safety Parameter Display Systems. In the 
Proceedings of the 24 th Annual Meeting of the Human Factors Society. Santa Monica, CA.

Woods, D. D. (1982): Operator Decision Behavior During the steam Generator Tube Rupture at the Ginna Nuclear Power Station. Research Report 82-1C57- CONRM-R2. Westinghouse R\&D, Pittsburg.

Wocds, D. D. (1984): Visual Momentum: A Concept to Improve the Cognitive Coupling of Ferson and Computer. Int. J. ManMachine Studies 21, pp. 229-244. 
in Systems Design

Jens Rasmussen

Department or group

Electronics

Group's own reg istration number ( $s$ )

$R-5-8 j$

\section{7 pages + tables + 4 illustrations}

Abstract

The present rapid development of advanced information technology and its use for support of operators of complex technical systems are changing the content of task analysis towards the analysis of mental activities in decision making. Automation removes the humans from routine tasks, and operators are left with disturbance control and critical diagnostic tasks, for which computers are suitable for support, if it is possible to match the computer strategies and interface formats dynamically to the requirenents of the current task by means of an analysis of the cognitive task.

Such a cognitive task analysis will not aim at a description of the information processes suited for particular control situations. It will rather aim at an analysis in order to identify the requirements to be considered along, various dimensions of the decision tasks, in order to give the user - i.e. a decision maker - the freedom to adapt his performance to systom requirements in a way which matches his process resources and subjective preferences. To serve this purpose, a number of analyses at various levels are needed to relate the control requirements of the system to the information processes required and to the processing resources offered by computers and humans. The paper discusses the cognitive task analysis in terms of the following domains: The problem domain, which is a representation of the functional properties of the system giving a consistent framework for identification of the control requirements of the system; the decision sequences required for typical situations; the mental strategies and heuristics which are effective and acceptable for the different decision functions; and the cognitive control mechanisms used, depending upon the level of skill which can/will be applied. Finally, the end-users' criteria for choice of mental stategies in the actual situation are considered, and the need for development of criteria for judging the ultimate user acceptance of computer support is discussed.

Availasle on request from Ris Library, Risф National Labor ory (Risø Bibliotek), Forgøgsanlag Risф), DK-4000 Roskilde, Denmark

Telephone: (03) 371212 , ext, 2262. Telex: 43116 